\title{
Efficacy and safety of anticoagulant therapy in patients with chronic cirrhosis complicated with portal vein thrombosis: what should we expert from a meta- analysis?
}

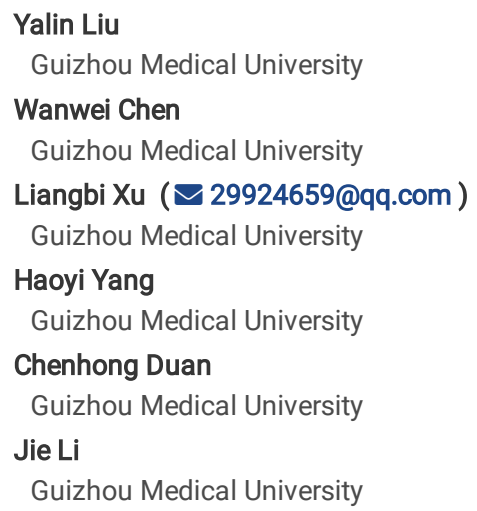

Keywords: anticoagulant therapy, chronic cirrhosis, portal vein thrombosis, LMWH, Warfain, AT-III, Nadroparin, phenprocoumon, VKA, recanalization, bleeding events, meta-analysis

Posted Date: May 23rd, 2020

DOI: https://doi.org/10.21203/rs.3.rs-28549/v1

License: @ (i) This work is licensed under a Creative Commons Attribution 4.0 International License. Read Full License 


\section{Abstract}

Background: Systematic review and meta-analysis were performed to evaluate efficacy and safety of anticoagulant therapy in patients with chronic cirrhosis complicated with portal vein thrombosis (PVT).

Methods: The PubMed, The Cochrane Library and Web of Science databases were searched. The odds ratio (OR) and risks ratio(RR) with 95\% Cl was pooled to calculate the difference in the rate of portal vein recanalization and occurrence of bleeding events between patients who received anticoagulation and those who did not. All meta-analysis were conducted by using a random-effects model.

Results: 8 studies with a total of 559 patients published between 2005 and 2019 were finally enrolled in our meta-analysis . The rate of portal vein recanalization was significantly higher with PVT who received anticoagulation and those who did not $(\mathrm{OR}=4.689,95 \%(95 \% \mathrm{Cl}=3.274-6.716, \mathrm{P}=0.000)$. And the pooled risk ratio of bleeding between the two groups was $0.828(95 \% \mathrm{Cl}=0.511-1.343, \mathrm{P}=0.444)$. The heterogeneity was not statistically significant among studies, Begg's funnel plot and Egger's linear regression test were performed to evaluate publicantion bias.

Conclusion: Anticoagulation therapy can significantly improve the recanalization rate of PVT patients with cirrhosis, and the bleeding related events caused by anticoagulation are relatively low, which is worthy of clinical promotion. However, more prospective trials are needed to know how to use anticoagulants.

\section{Background}

Portal vein thrombosis (PVT) refers to thrombosis in the trunk of the portal vein or its in trahepatic branches for various reasons. The prevalence of PVT in cirrhotic patients was approximately $10 \%-25 \%(1)$. As a common complication of decompensated cirrhosis, PVT can increase pressure within the portal vein, deteriorate liver function, and increase the risk of portal hypertension-related complications. In general, visceral venous thrombosis requires anticoagulant therapy. PVT itself causes increase of portal pressure, which will worsen esophageal and gastric varices and increase the risk of bleeding. However, anticoagulant therapy in patients with liver cirrhosis may induce gastrointestinal (GI) bleeding. The relationships among these three conditions are quite complex, making the clinical treatments even more challenging. The 2017 Billroth III(2) recommends the sequential use of low-molecular-weight heparin and vitamin $\mathrm{K}$ antagonists (VKAs) for anticoagulation in patients with acute or chronic progressive non-cirrhotic non-malignant PVT or acute non-malignant PVT; and anticoagulation may also be applied for symptomatic malignant PVT. Meanwhile, both Billroth III and Baveno VI(3)guidelines recommend the use of anticoagulation therapy for PVT in liver transplant candidates on a waiting list, in an attempt to lower the post-transplant mortality and morbidity; and anticoagulation maintenance before transplantation can prevent occurrence of re-thrombosis.

However, for patients with chronic liver cirrhosis and portal hypertension, whether the use of anticoagulants markedly increases the portal recanalization rate or increases the risk of bleeding remains controversial. As there is no definite recommendation on anticoagulation therapy for cirrhotic PVT patients, analysis of relevant data is particularly important. The following questions remained to be answered: are anticoagulants effective for PVT treatment? Compared with non-users of anticoagulants, do patients treated with anticoagulants have higher portal recanalization rate? Do they have higher risk of GI bleeding, even if recanalization of the portal vein is achieved?

It is generally acknowledged that meta-analysis is a powerful statistic tool to overcome the limitation of different sample sizes from individual studies and to generate the best estimation. In our current study, we aimed to evaluate the impact of anticoagulation therapy on portal recanalization rate and bleeding risk in patients with cirrhotic PVT. For this purpose, we performed a meta-analysis of all eligible articles to quantify the prognostic value of anticoagulation therapy in cirrhotic PVT patients.

\section{Methods Search strategy}

We performed a comprehensive literature search of articles through the following databases without date limitation: PubMed, The Cochrane Library and Web

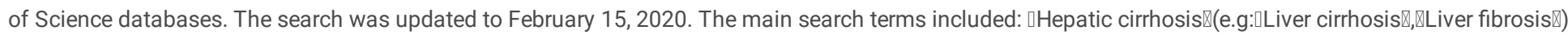

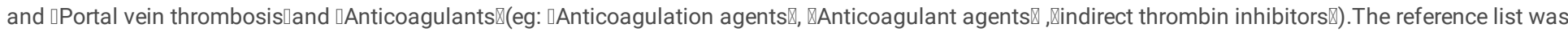
also checked for relevant articles.

\section{Inclusion And Exclusion Criteria}

Inclusion criteria for selecting the studies for this meta-analysis were as follows criteria: (i) studied patients with liver cirrhosis. Liver cirrhosis was diagnosed on the basis of clinical, laboratory, and imaging studies or liver biopsy. All adult patients with cirrhosis of any etiology; (ii) Imaging diagnosis of malignant portal vein thrombosis; (iii) Recanalization of portal vein thrombosis in anticoagulation group and non anticoagulation group has been reported .Exclusion criteria were as follows: (i) abstracts, letters, case reports, reviews or nonclinical studies; (ii) studies were not written in English; (iii) Anticoagulation after splenectomy ; (iv) Only anticoagulation after TIPS ;(v) Anticoagulation associated with Budd Chiari syndrome ;(vi) EVL after anticoagulantion ;(vii)studies with insufficient data for estimating odd ratio (OR) and 95\% confidence interval (Cl);(viii) studies had duplicate data or repeat analysis.

\section{Data Extraction And Quality Assessment}


All candidate articles were evaluated and extracted by two independent authors (Liu Yalin and Chen Wanwei). Articles that could not be categorized based on title and abstract alone were retrieved for full-text review. If disagreement occurred, two authors discussed and arrived at consensus with a third author (Xu Liangbi). For each study, the following items was recorded: first author, year of publication, country, total number of cases and gender, follow ups, treatment strategy, number of PVT recanalization in treatment group and control group and Number of bleeding events in two groups. The Newcastle-Ottawa Scale (NOS) was used to assess each of the included studies quality by two independent authors (Liu Yalin and Chen Wanwei). The NOS consists of three parts: selection ( $0-4$ points), comparability ( $0-2$ points), and outcome assessment ( $0-3$ points). NOS scores of $\geq 6$ were assigned as high-quality studies.

\section{Statistical analysis}

The odds ratio (OR) and risks ratio(RR) with $95 \% \mathrm{Cl}$ was pooled to calculate the difference in the rate of portal vein recanalization and occurrence of bleeding events between patients who received anticoagulation and those who did not. Cochran's $Q$ test and Higgins I-squared statistic were undertaken to assess the heterogeneity of the included trials. Both Peto method and random effects ( $D-L$ herterogeneity) models were used to calculate the pooled ORs, RRs and $95 \% \mathrm{Cls}$. A Pheterogeneity $<0.10$ or $\mathrm{I} 2>50 \%$ suggested significant heterogeneity in the literature and a random-effect model was used. Otherwise, the fixedeffects model was adopted. Subgroup analysis, sensitivity analysis were conducted to explore and explain the diversity (heterogeneity) among the results of different studies. Publication bias was assessed by visual inspection of Begg's funnel plot and the possibility of publication bias was conducted by Egger test. All $p$-values were two-sided. A 2-sided $p<0.05$ was considered statistical significant. All the statistical analyses were performed using STATA statistical software version 15.0 (STATA, College Station, TX).

\section{Results}

\section{Study characteristics}

The initial search strategies retrieved a total of 1466 articles. After meticulous inspection of the articles, 8 studies with a total of 559 patients published between 2005 and 2019 were finally enrolled in our meta-analysis(4-11). The processes of study selection were summarized in the flow diagram(Fig. 1). Among them, participants in five studies were Caucasian and in the other three were Asian. Two studies were Intaly, one in France, China, Korea, Japan, Austria, Portugal. According to the type of anticoagulants, 1 studies employed LMWH along, 2 studies employed Warfain along, 1 studies employed AT-III alone, 1 studies employed Nadroparin along, 1 studies employed Warfain and/or LMWH, 1 studies employed LMWH and phenprocoumon, 1 studies employed LMWH and/or VKA. All studies were 8 point by NOS. (Table 1).

\subsection{Comparison of portal vein recanalization between anticoagulation and non-anticoagulation groups}

The rate of portal vein recanalization between cirrhotic patients with PVT who received anticoagulation and those who did not was compared in 8 studies. The Peto method pooled OR was $4.689(95 \% \mathrm{Cl}=3.274-6.716, \mathrm{P}=0.000)$ (Supplementary Fig. 2). The heterogeneity was not statistically significant among studies $(P=0.827 ; 12=0.000 \%)$, Begg's funnel plot and Egger's linear regression test were performed to evaluate publicantion bias. OR publication bias was not detected, publication bias was detected for $\mathrm{OR}(\mathrm{Pr}>|\mathrm{z}|=0.174$ for Begg's test and $\mathrm{P}>|\mathrm{t}|=0.251$ for Egger's $)$.

The sensitivity analysis(Supplementary Fig. 3) of the 8 articles we studied shows that after the exclusion of Marco senzolo (2012), the combined or value and $95 \% \mathrm{Cl}$ are most affected. According to the published literature, prospective or regression studies were divided into two categories for subgroup analysis(Supplementary Fig. 4), and there was no significant heterogeneity between them. The ergonomics was not statistically significant among students (prospective $\mathrm{P}=0.497 ; 12=0.000 \%$ ), retrospective $\mathrm{P}=0.906 ; 12=0.000 \%$ )

\subsection{Comparison of bleeding events between anticoagulation and non anticoagulation groups}

The risk of bleeding events between cirrhotic patients with PVT who received anticoagulation and those who did not was compared in 8 studies. The D-L method pooled RR was $0.828(95 \% \mathrm{Cl}=0.511-1.343, \mathrm{P}=0.444)$ (Supplementary Fig. 5). The heterogeneity was not statistically significant among studies $(\mathrm{P}=$ $0.375 ; 12=7.1 \%$ ). Begg's funnel plot and Egger's linear regression test were performed to evaluate publicantion bias. OR publication bias was not detected, publication bias was detected for $\mathrm{OR}(\mathrm{Pr}>|\mathrm{z}|=0.536$ for Begg's test and $\mathrm{P}>|\mathrm{t}|=0.982$ for Egger's).

\section{Discussion}

Our meta-analysis pooled the outcomes of 559 cirrhotic PVT patients in 8 individual studies, and the results showed that anticoagulation therapy achieved a significantly higher portal recanalization rate $(\mathrm{OR}, 4.689 ; 95 \% \mathrm{Cl}, 3.274-6.716)(P=0.000)$. The relative risk of bleeding was low, with a pooled $\mathrm{RR}$ of 0.828 $(95 \% \mathrm{Cl}, 0.522-1.343, P=0.444)$.

The occurrence of PVT in cirrhotic patients increases the risk of portal hypertension and is considered to be an adverse prognostic factor. It usually exacerbates the deterioration of liver function and increases the incidence of portal hypertension-related bleeding. The pathogenic mechanism of cirrhosis accompanied by PVT is still not fully understood. It was believed that the disorders in the synthesis of coagulation factors in cirrhotic patients would increase the risk of bleeding, which, however, is contradictory to non-malignant PVT in patients with cirrhosis. Some recent studies (12-14)have suggested that PVT in cirrhotic patients results from a variety of factors including the decreased portal vein flow velocities, portal vein lymphangitis, and portal fibrosis. It may also be because that the poor liver function in cirrhotic patients disrupts the balance between pro- and anti-coagulation factors. It also raises the question whether the use of anticoagulants may break such a vicious circle by achieving portal recanalization to lower portal pressure and thus improve liver function and reduce portal hypertension-related complications. More recent studies have evaluated the efficacies and risks of different anticoagulants in treating PVT in 
cirrhotic patients, and their findings are helpful for determining anticoagulation strategies for these patients. Therefore, we reviewed the published studies and undertook meta-analysis to derive a more precise estimation of the prognostic value of anticoagulant use for PVT in cirrhotic patients.

Unfortunately, many studies have been focused on the anticoagulative effects and relevant complications before and after anticoagulant therapy for PVT in cirrhotic patients. Few randomized controlled trials have been performed on the anticoagulation versus non-anticoagulation for PVT in cirrhotic patients. In addition, the sample sizes of the included studies were small, which decreased the representativeness of our conclusions.

Nevertheless, there was non-significant heterogeneity across the included studies in OR for portal vein recanalization $\left(P=0.827 ; I^{2}=0.000 \%\right)$. As there was no significant heterogeneity, we performed sensitivity analysis, which showed that Marco Senzolo's article (2012) had the highest impact on the pooled OR value and $95 \% \mathrm{Cl}$. Also, there was non-significant heterogeneity across the included studies in RR for bleeding risk $\left(P=0.495 ; I^{2}=0.000 \%\right)$.

Both prospective and retrospective studies (predominantly prospective studies) were included in our analysis, and all of them were of high quality. The main limitation of our study is that the number of eligible studies was small in the establishment of anticoagulation values. Both Egger's test and Begg's test had lower power when the number of studies included in meta-analysis was less than 10. Hence, the publication bias might not be detected by Egger's and Begg's tests. In addition, only English-language articles were included, which may generate publication bias.

\section{Conclusion:}

In summary, anticoagulant use is associated with a high vascular recanalization rate and a low risk of bleeding in cirrhotic patients with PVT. As shown in clinical evaluations, anticoagulant use for PVT may be attempted after the contraindications to the use of anticoagulant drugs are ruled out.

Currently, warfarin or low-molecular-weight heparin is commonly used for PVT. Both of them require frequent INR testing, which causes difficulties in patient compliance and follow-up. However, the currently available controlled studies on oral anticoagulants were still limited by their small number and sample sizes, and more related RCTs are expected. Finally, the duration of anticoagulant use, the rate of PVT recurrence after the drug is discontinued, and the optimization of currently available anticoagulation regimes warrant further investigations.

\section{Declarations}

\section{Ethics approval and consent to participate}

This article does not contain any studies with human or animal subjets.

\section{Consent for publication}

This article is agreed to publish

\section{Availability of data and materials}

All data and materials from the internet

\section{Contributors' statement:}

Liu Yalin and Chen wanwei contributed to the conception and design of the study.

All the authors participated in writing the manuscript, and approved the final draft.

Liu Yalin $\square$ Xu Liangbi and Yang Haoyi undertook the literature search and retrieval

of publications.

Liu Yalin aDuan Chenhong and Li Jie performed statistical analysis.

\section{Conflicts of Interest:}

All the Authors approved the submitted version of this manuscript and declare that no conflict of interest exists.

Source of founding: none

Acknowledgements

Not applicable

\section{References}

1. TSOCHATZIS EA, SENZOLO M, GERMANI G, GATT A, BURROUGHS AK. Systematic review: portal vein thrombosis in cirrhosis. Aliment Pharmacol Ther. 2010;31:366-74. 
2. Reiberger T, Püspök A, Schoder M, Baumann-Durchschein F, Bucsics T. Austrian consensusguidelinesonthemanagement and treatment ofportalhypertension(BillrothIII). Wien Klin Wochenschrift. 2017;129:135-58.

3. Roberto de Franchis M, AGAF. EXPANDING CONSENSUS IN. PORTAL HYPERTENSION Report of the Baveno VI Consensus Workshop: stratifying risk and individualizing care for portal hypertension. Journal of Hepatology 2015.

4. Francoz C, Belghiti J, Vilgrain V, Sommacale D, Paradis V, Condat B. Splanchnic vein thrombosis in candidates for liver transplantation: usefulness of screening and anticoagulation. Gut. 2005;54:691-7.

5. Senzolo M, Sartori TM, Rossetto V, Burra P, Cillo U, Boccagni P. Prospective evaluation of anticoagulation and transjugular intrahepatic portosistemic shunt for the management of portal vein thrombosis in cirrhosis. Liver International. 2012;32:919-27.

6. Chung JW, Kim GH, Lee JH, Ok KS, Jang ES, Jeong S-H, Kim J-W. Safety, efficacy, and response predictors of anticoagulation for the treatment of nonmalignant portal-vein thrombosis in patients with cirrhosis: a propensity score matching analysis. Clinical molecular hepatology. 2014;20:384-91.

7. Chen H, Liu L, Qi X, He C, Wu F. Efficacy and safety of anticoagulation in more advanced portal vein thrombosis in patients with liver cirrhosis. European Journal of Gastroenterology Hepatology. 2016;28:82-9.

8. Hidaka H, Kokubu S, Sato T, Katsushima S, Izumi N, Igura T, Asahara S. Antithrombin III Administration for Portal Vein Thrombosis in Patients with Liver Disease: A Randomized Double-Blind Controlled Trial. Hepatol Res. 2018;48:E107-16.

9. Pettinari, Vukotic R, Stefanescu H, Pecorelli A, Morelli M, Grigoras C. clinical Impact and Safety of Anticoagulants for Portal Vein thrombosis in cirrhosis. The American College of Gastroenterology 2018.

10. Scheiner B, Stammet PR, Pokorny S, Bucsics T, Schwabl P, Brichta A, Thaler J. Anticoagulationinnon-malignantportal veinthrombosisis safe and improveshepaticfunction. Wien Klin Wochenschrift 2018;18.

11. Ferreira CN, Reis D. Helena Cortez-Pinto, Rui Tato Marinho, Afonso Gonçalves, Sónia Palma, Inês Leite. Anticoagulation in Cirrhosis and Portal Vein Thrombosis Is Safe and Improves Prognosis in Advanced Cirrhosis. Dig Dis Sci. 2019;64:2671-83.

12. Turco L, Raucourt Ed, Valla D-C, Villa E. Anticoagulation in the cirrhotic patient. J Hepatol. 2019;1:227-39.

13. Qi X, Li H, Liu X, Yao H, Han G, Hu F, Shao L, et al. Novel insights into the development of portal vein thrombosis in cirrhosis patients. Expert Rev Gastroenterol Hepatol. 2015;9:1421-32.

14. Zocco MA, Di Stasio E, De Cristofaro R, Novi M, Ainora ME, Ponziani F, Riccardi L, et al. Thrombotic risk factors in patients with liver cirrhosis: correlation with MELD scoring system and portal vein thrombosis development. J Hepatol. 2009;51:682-9.

\section{Table}

Table 1: Characteristics of studies included in the meta-analysis 


\begin{tabular}{|c|c|c|c|c|c|c|c|c|c|c|c|}
\hline \multirow{3}{*}{$\begin{array}{l}\text { Author/ } \\
\text { Year }\end{array}$} & \multirow{3}{*}{$\begin{array}{l}\text { Study } \\
\text { Desing }\end{array}$} & \multirow[t]{3}{*}{ Region } & \multirow[t]{3}{*}{ Ethnicity } & \multirow{3}{*}{$\begin{array}{l}\text { Study } \\
\text { Population }\end{array}$} & \multirow[t]{3}{*}{ Treatment } & \multirow{3}{*}{$\begin{array}{l}\text { AT } \\
\text { patients } \\
\text { /control(n) }\end{array}$} & \multirow{3}{*}{$\begin{array}{l}\text { No. } \\
(M / F)\end{array}$} & \multirow{3}{*}{$\begin{array}{l}\text { Age } \\
\text { (years) }\end{array}$} & \multicolumn{3}{|c|}{ Indexes of LC severity } \\
\hline & & & & & & & & & MELD & child & pugh \\
\hline & & & & & & & & & & A & B \\
\hline \multirow[t]{2}{*}{$\begin{array}{l}\text { Francoz } \\
(2005)\end{array}$} & \multirow[t]{2}{*}{$\mathrm{P}$} & \multirow[t]{2}{*}{$\begin{array}{l}\text { Clichy, } \\
\text { France }\end{array}$} & \multirow[t]{2}{*}{ Caucasian } & \multirow{2}{*}{$\begin{array}{l}\text { Cirrhotic } \\
\text { Patients } \\
\text { listed for } \\
\text { transplantation }\end{array}$} & \multirow[t]{2}{*}{ LMWH and VKA } & 19 & $13 / 6$ & $\begin{array}{l}48.7 \pm \\
7.5\end{array}$ & $\begin{array}{l}12.8 \pm \\
4.3\end{array}$ & 2 & 13 \\
\hline & & & & & & 10 & $7 / 3$ & $\begin{array}{l}52 \pm \\
5.7\end{array}$ & $\begin{array}{l}11.8 \pm \\
6.2\end{array}$ & 2 & 6 \\
\hline \multirow[t]{2}{*}{$\begin{array}{l}\text { Marco } \\
\text { Senzolo } \\
(2012)\end{array}$} & \multirow[t]{2}{*}{$\mathrm{P}$} & \multirow[t]{2}{*}{$\begin{array}{l}\text { Padua, } \\
\text { Italy }\end{array}$} & \multirow[t]{2}{*}{ Caucasian } & \multirow[t]{2}{*}{$\begin{array}{l}\text { cirrhosis } \\
\text { with } \\
\text { non-tumoral PVT }\end{array}$} & $\begin{array}{l}\text { Nadroparin } \\
\text { and/or } \\
\text { LWMH }\end{array}$ & $\begin{array}{l}33 \\
\text { (include } 7 \\
\text { tips ) }\end{array}$ & $\begin{array}{l}25 / 10(2 \\
\text { untreated) }\end{array}$ & $\begin{array}{l}55.5 \pm \\
5\end{array}$ & $\begin{array}{l}12.6 \pm \\
3.7\end{array}$ & 11 & 16 \\
\hline & & & & & & 21 & $13 / 8$ & $\begin{array}{l}52.3 \pm \\
4\end{array}$ & $\begin{array}{l}13.7 \pm \\
3.6\end{array}$ & 5 & 9 \\
\hline \multirow{2}{*}{$\begin{array}{l}\text { Jung Wha } \\
\text { Chung } \\
(2014)\end{array}$} & \multirow[t]{2}{*}{$\mathrm{R}$} & \multirow[t]{2}{*}{$\begin{array}{l}\text { Seoul } \\
\text { Korea }\end{array}$} & \multirow[t]{2}{*}{ Asian } & \multirow{2}{*}{$\begin{array}{l}\text { Cirrhotic patients } \\
\text { with non-malignant } \\
\text { PVT }\end{array}$} & warfain & 14 & $10 / 4$ & $\begin{array}{l}59.4 \pm \\
12.0\end{array}$ & \multirow[t]{2}{*}{ NR } & 6 & 8 \\
\hline & & & & & & 14 & $11 / 3$ & $\begin{array}{l}58.7 \pm \\
13.2\end{array}$ & & 7 & 6 \\
\hline \multirow[t]{2}{*}{$\begin{array}{l}\text { Hui } \\
\text { Chen(2016) }\end{array}$} & \multirow[t]{2}{*}{$\mathrm{R}$} & \multirow[t]{2}{*}{$\begin{array}{l}\text { Xian, } \\
\text { China }\end{array}$} & \multirow[t]{2}{*}{ Asian } & \multirow[t]{2}{*}{$\begin{array}{l}\text { Cirrhotic patients } \\
\text { with non-malignant } \\
\text { PVT }\end{array}$} & \multirow[t]{2}{*}{ warfain } & 30 & $23 / 7$ & $\begin{array}{l}44.97 \\
\pm 12.3\end{array}$ & $\begin{array}{l}9.9 \pm \\
4.04\end{array}$ & NR & \\
\hline & & & & & & 36 & $24 / 12$ & $\begin{array}{l}47.86 \\
\pm 10.6\end{array}$ & $\begin{array}{l}8.9 \pm \\
3.01\end{array}$ & & \\
\hline $\begin{array}{l}\text { Hishi } \\
\text { Hidaka } \\
(2018)\end{array}$ & $\mathrm{P}$ & Japan & Aisan & $\begin{array}{l}\text { Cirrhotic } \square \\
\text { idiopathic } \\
\text { portal hypertension } \\
\text { or }\end{array}$ & AT-III & 36 & $26 / 10$ & $\begin{array}{l}66.0 \\
(39- \\
80)\end{array}$ & NR & 6 & 23 \\
\hline & & & & cholangiocarcinoma & & 36 & $20 / 16$ & 69.5 & & 6 & 24 \\
\hline & & & & $\begin{array}{l}\text { patients with non- } \\
\text { malignant PVT }\end{array}$ & & & & $\begin{array}{l}\text { (48- } \\
86)\end{array}$ & & & \\
\hline $\begin{array}{l}\text { Bernhard } \\
\text { Scheiner } \\
(2018)\end{array}$ & $\mathrm{R}$ & $\begin{array}{l}\text { Vienna, } \\
\text { Austria }\end{array}$ & Caucasian & $\begin{array}{l}\text { Cirrhotic patients } \\
\text { with non-malignant } \\
\text { PVT }\end{array}$ & $\begin{array}{l}\text { LMWH and } \\
\text { phenprocoumon }\end{array}$ & $\begin{array}{l}\text { 12(long- } \\
\text { term AT) }\end{array}$ & $32 / 19$ & $\begin{array}{l}52.9 \pm \\
12.5\end{array}$ & $\begin{array}{l}\text { MELD } 13 \\
\text { child puc }\end{array}$ & $\begin{array}{l}6 \pm 6.5 \\
: \text { A14 }\end{array}$ & $\mathrm{B} 19 \square \mathrm{C}$ \\
\hline & & & & & & $\begin{array}{l}36 \text { (without } \\
\text { long-trem } \\
\text { AT) }\end{array}$ & & & & & \\
\hline $\begin{array}{l}\text { Pettinari } \\
2018\end{array}$ & $P$ & $\begin{array}{l}\text { Bologna, } \\
\text { Italy }\end{array}$ & Caucasian & $\begin{array}{l}\text { cirrhosis } \\
\text { with } \\
\text { non-tumoral PVT }\end{array}$ & $\begin{array}{l}\text { LMWH or } \\
\text { fondaparinux or } \\
\text { VKA }\end{array}$ & 81 & $56 / 25$ & $\begin{array}{l}57.9 \pm \\
11.1\end{array}$ & $\begin{array}{l}\text { MELD } \\
<943 \\
(23.6 \%)\end{array}$ & 43 & 33 \\
\hline & & & & & & 101 & $74 / 27$ & $\begin{array}{l}57.7 \pm \\
11.3\end{array}$ & $\begin{array}{l}\text { MELD } \\
<914 \\
(13.9 \%)\end{array}$ & 37 & 45 \\
\hline $\begin{array}{l}\text { Carios } \\
\text { Noronha } \\
\text { Ferreia }\end{array}$ & $\mathrm{P}$ & Portugal & Caucasian & $\begin{array}{l}\text { cirrhosis } \\
\text { with } \\
\text { non-tumoral PVT }\end{array}$ & $\begin{array}{l}\text { Warfar and/or } \\
\text { LMWH }\end{array}$ & 37 & $28 / 9$ & $59 \pm 8$ & $14 \pm 6$ & 12 & 16 \\
\hline & & & & & & 43 & $25 / 18$ & $\begin{array}{l}60 \pm \\
10\end{array}$ & $16 \pm 7$ & 9 & 18 \\
\hline
\end{tabular}

\section{Figures}




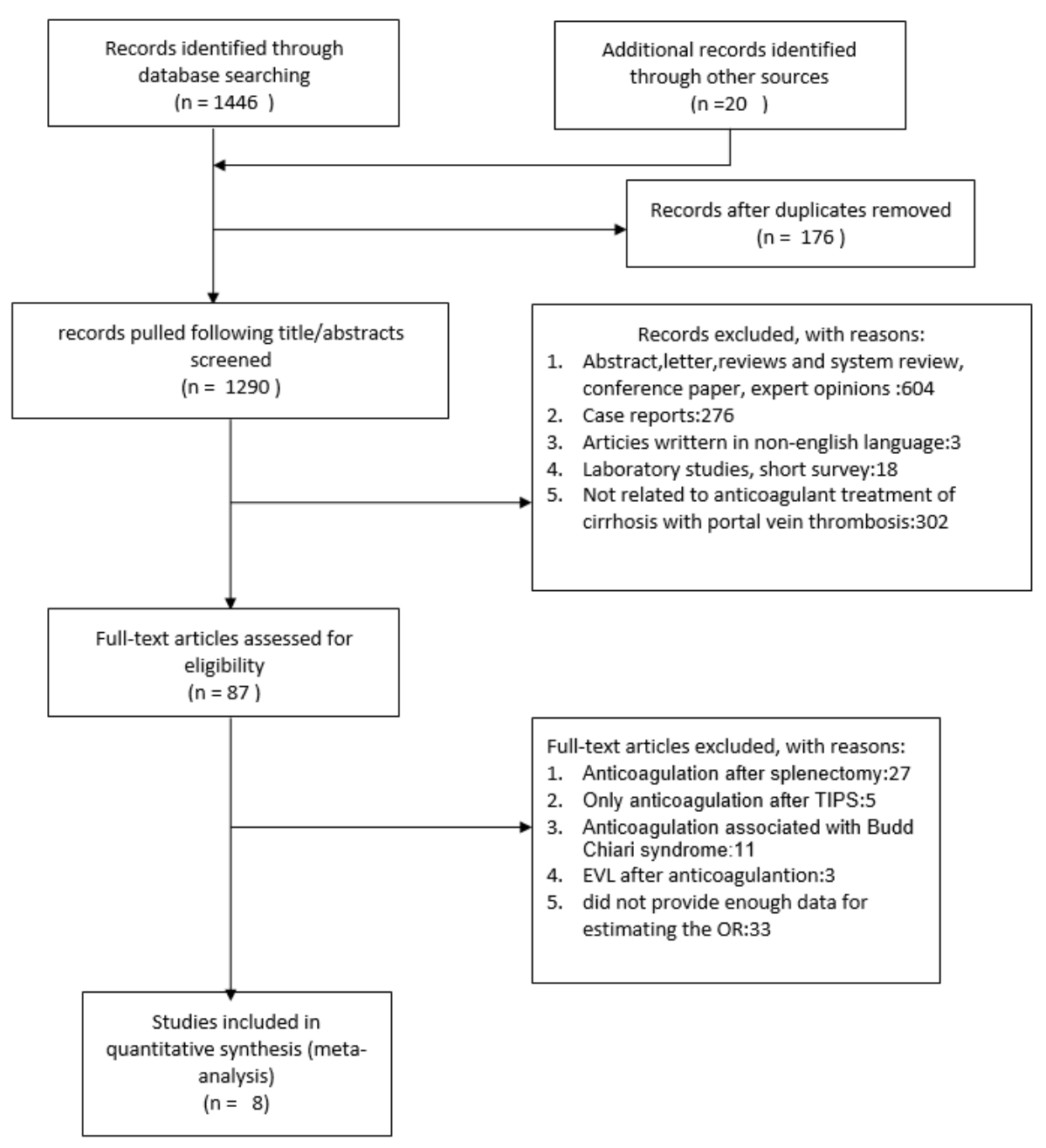

\section{Figure 1}

Flowchart of study inclusion 


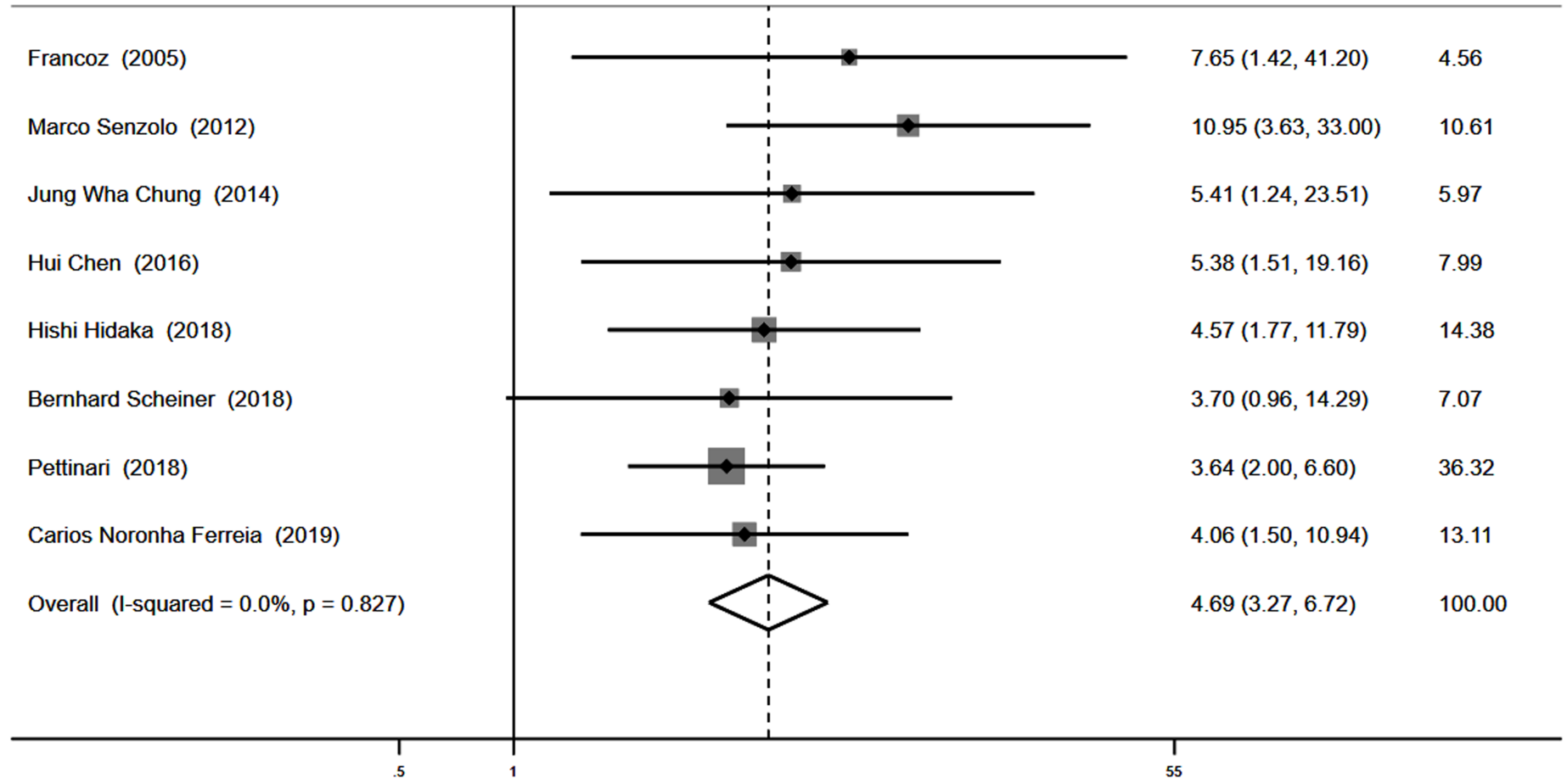

\section{Figure 2}

Forest plots of the difference in the rate of vein recanalization between cirrhotic patients with PVT who received anticoagulation and those who did not. 


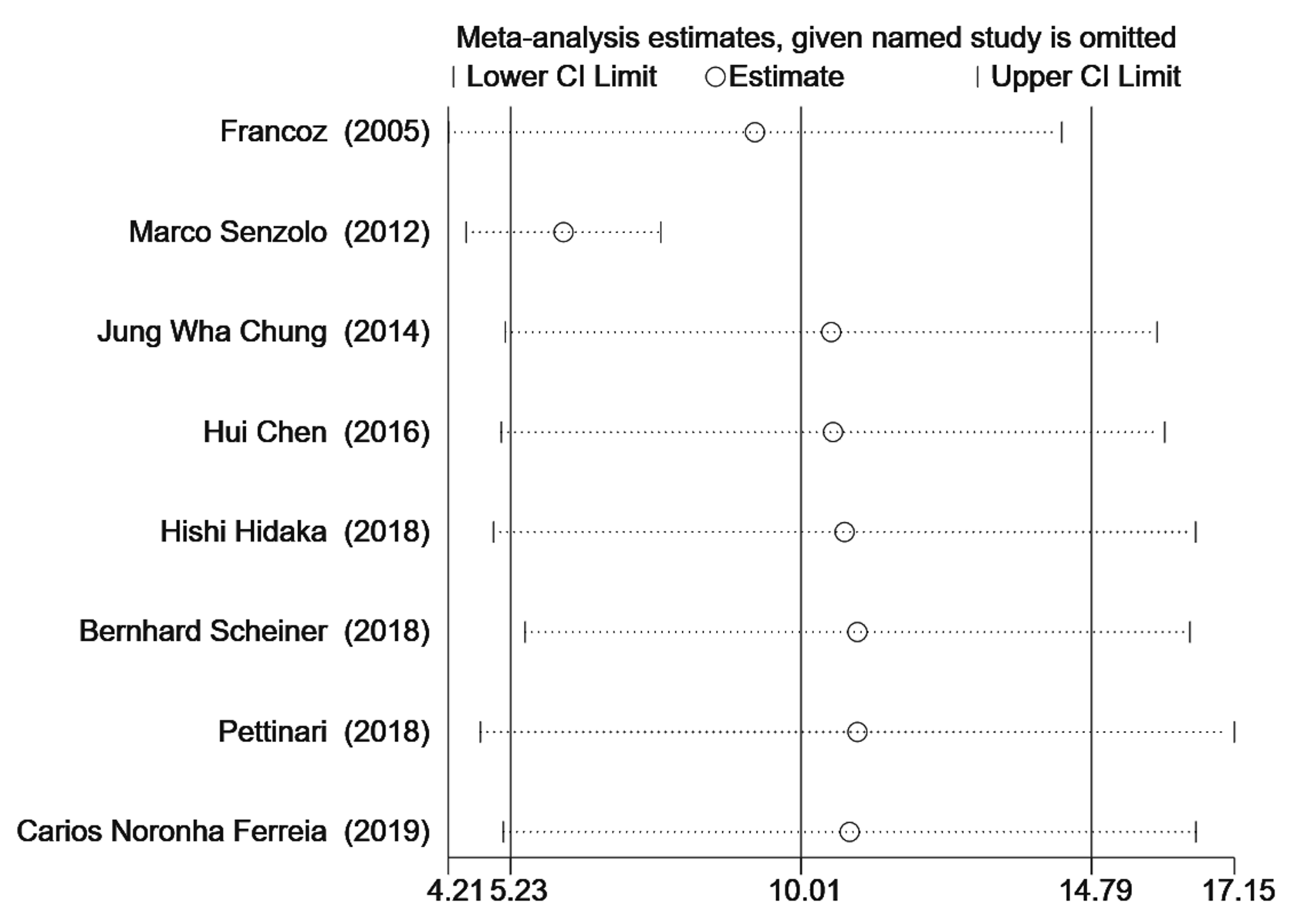

Figure 3

The sensitivity analysis about t of the 8 articles . 


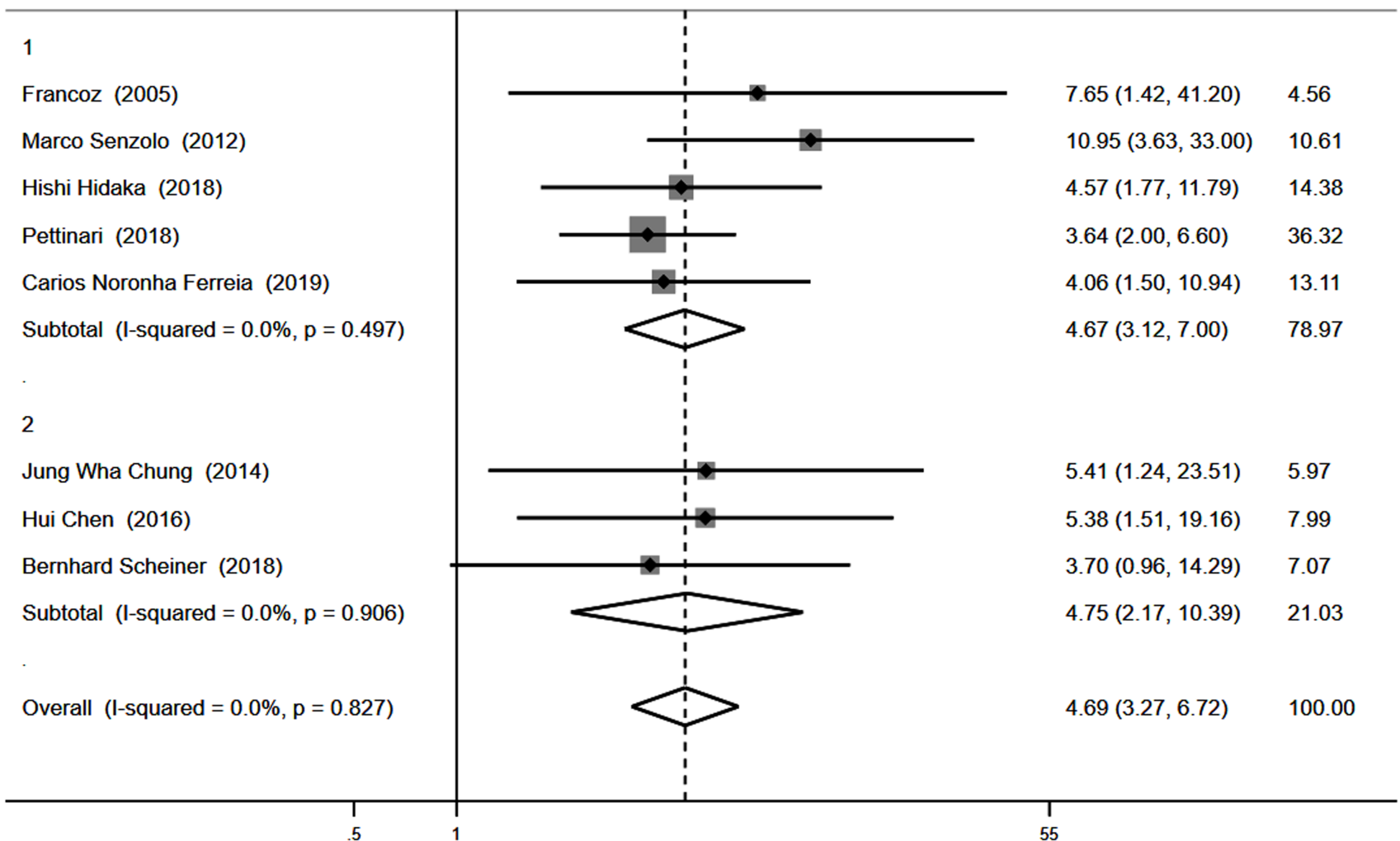

\section{Figure 4}

The prospective or regression studies were divided into two categories for subgroup analysis. 
ID

$\mathrm{RR}(95 \% \mathrm{Cl})$

Weight

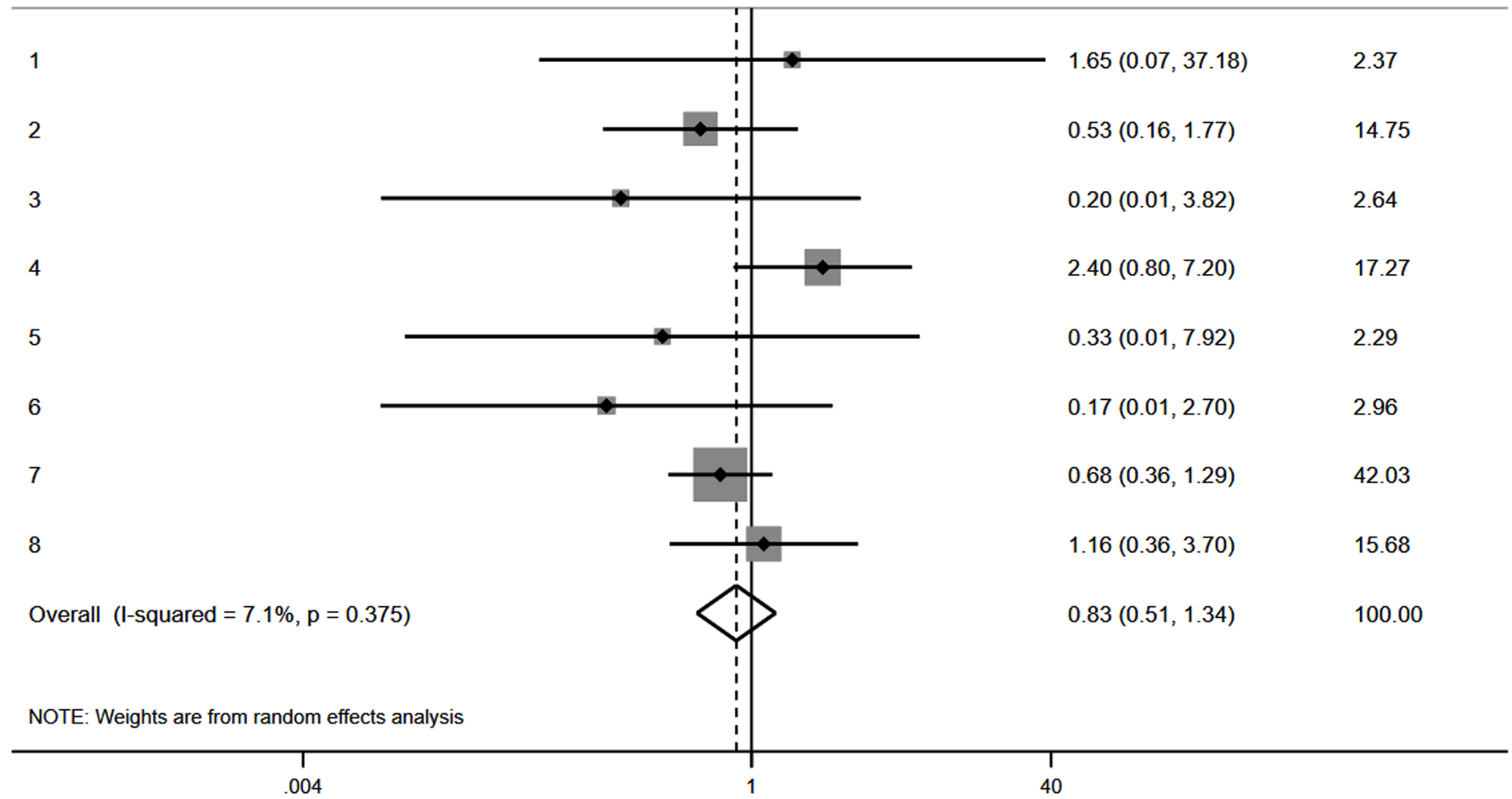

Figure 5

Forest plots of the difference in the risk of bleeding events between cirrhotic patients with PVT who received anticoagulation and those who did not. 